\title{
Ağır Metallerin Çeşitli Gözenekli Malzemeler Üzerinde Adsorpsiyonu
}

\author{
Ayşe Dilek ATASOY1 ${ }^{10}$, Benan YAZICI KARABULUT ${ }^{*}$ [C] \\ 1,2Harran Üniversitesi, Mühendislik Fakültesi, Çevre Mühendisliği Bölümü, 63190, Şanlıurfa, Türkiye
}

(Alınıș / Received: 17.01.2019, Kabul / Accepted: 03.07.2019, Online Yayınlanma / Published Online: 30.08.2019)

Anahtar Kelimeler

Adsorpsiyon,

Boksit,

Montmorillonit kili,

Tuğla kili
Özet: Bu çalışma ile çevre ve insan sağlığı açısından büyük sorunlar oluşturan ağır metallerin oldukça düşük maliyetli, ekonomik ve kolay elde edilebilen malzemeler ile giderilebilirliği araştırılmıştır. Çalışmada, ekonomik ve giderim verimi yüksek bir yöntem olan adsorpsiyon yöntemi kullanılarak, sulardan $\mathrm{Cu}^{+2}, \mathrm{Zn}^{+2}, \mathrm{~Pb}^{+2} \mathrm{ve} \mathrm{Ni}^{+2}$ giderimi amaçlanmıștır. Batch metoduna göre yapılan çalışmada adsorban olarak boksit, montmorillonit kili ve tuğla kili kullanılmıștır. Bakır ve çinkonun boksit ve montmorillonit kili üzerindeki adsorpsiyon denge süresine 1 saatte, kurşun ve nikel adsorpsiyonuna $20 \mathrm{dk}$ da, tuğla kili adsorbanı üzerinde kurşun adsorpsiyonuna $40 \mathrm{dk}$ 'da, nikel adsorpsiyonuna ise 4 saatte ulaşılmıștır. Her kil tipi için optimum adsorban dozları belirlenmiştir. Bakır, çinko, kurşun ve nikel ağır metallerinin adsorbanlar üzerindeki adsorpsiyonu hem Freundlich hem de Langmuir izotermi ile iyi uyum sağladığı görülmüștür.

\section{Adsorption of Heavy Metals with Various Porous Materials}

Keywords

Adsorption,

Bauxite,

Montmorillonite clay,

Clay brick

\begin{abstract}
The removal alternatives of toxic heavy metals by the cheap and easy supplied materials were investigated in this study. Especially the heavy metals cause very important problems in the environment. The aim of the study was to remove $\mathrm{Cu}^{+2}, \mathrm{Zn}^{+2}, \mathrm{~Pb}^{+2}$ and $\mathrm{Ni}^{+2}$ from the water by the cheap and the effective adsorption method. Batch method was used in the study and several porous materials such as bauxite, montmorillonite clay and clay brick were used as the adsorbents. To reach equilibration time, copper and zinc adsorption on montmorillonite and bauxite took an hour, lead and nickel adsorption on montmorillonite took 20 minutes, lead adsorption on clay brick took 40 minutes and nickel adsorption on clay bricks took 4 hours. Optimum adsorbent doses were determined for each clay type. Experimental data for all heavy metals adsorption on adsorbents fitted well with both Langmuir and Freundlich equations.
\end{abstract}

\section{Giriş}

Gelișen endüstrilerin çeşitli çalıșma alanlarında metal ve kimyasal kullanımının artmasıyla birlikte atık sulardaki ağır metal miktarları da artmaktadır. Bu durum da insan sağlığı açısından ve doğanın dengesini korumak adına çok büyük riskler taşımaktadır. Özellikle ağır metal endüstrilerinin toprağı ve suyu kirletmesi, havaya karışan zararlı maddelerin yağmur, kar gibi doğa olaylarıyla suya ve toprağa karışması, evsel atık suların toprak ve suya karışması, denize dökülen petrol türevlerinin ve katı atık maddelerin artış göstermesi gibi pek çok örnek, doğanın dengesini bozmakta ve canlı hayatını tehdit etmektedir. Sulardan ağır metal giderim sorunu her geçen gün daha da önem kazanmaktadır. As, Cd, Cr, $\mathrm{Cu}, \mathrm{Pb}, \mathrm{Mn}, \mathrm{Ni}, \mathrm{Zn}$ gibi çeșitli ağır metallerin toksik ve kanserojen etkileri vardır. Aynı zamanda canlı organizmalarda birikme eğilimi de gösterirler. Bu birikim ağır metal konsantrasyonlarının önemini bir kat daha fazla arttırmaktadır [1].

Adsorpsiyon, atık arıtımında düşük maliyetli ve çevre dostu olması sebebiyle en çok tercih edilen ileri arıtım yöntemlerinden biridir. Aktif karbon en çok kullanılan adsorban çeşididir. Ancak pahalı ve geri kazanımının zor olması nedeniyle ucuz ve doğal adsorbanlar bulma gereksinimi doğmuştur. Ucuz ve doğal olan bentonit, zeolit gibi killer adsorpsiyon işlemlerinde çoğunlukla kullanılmaktadır [2]. Bamgbose vd. (2010), sulu çözeltilerde demir ve kadmiyum iyonlarını uzaklaştırmak için, $25{ }^{\circ} C^{\prime}$ de konsantrasyon ve temas süresi gibi parametreler çalışmışlardır. Deneyler batch metodu ile yapılmıştır. 
Sonuçlar metal iyonları adsorpsiyonu için kitosanın adsorpsiyon kapasitesinin yüksek olduğunu ortaya koymuştur. FTIR çalışmasında kitosan ve metal kitosan komplekslerinin karakteristik pikleri incelenmiştir. Demir ve kadmiyum adsorpsiyon kinetiği tüm konsantrasyon değerleri Langmuir izotermi kullanıldığında tanımlanamamış fakat deneysel veriler Freundlich izotermi için uygun bulunmuştur [3]. Bamidele ve Emmanuel (2010), tarafından yapılan çalışmada sülfat ve fosfatla modifiye edilmiş bentonit kilinin $\mathrm{Cu}^{+2}$ ve $\mathrm{Zn}^{+2}$ için adsorpsiyon ve katyon değişim kapasitesi incelenmiş ve yüksek adsorpsiyon ve katyon değişim kapasiteleri elde edilmiştir. Parametreler Freundlich ve Langmuir izotermlerine göre değerlendirilmiş, Langmuir izoterminin daha iyi uyduğu görülmüştür [4]. Wang ve Li (2011), tarafından yapılan çalışmada, Çin'de Songhua Nehri üzerinde toplanan yüzeysel sediment örneklerinden elde edilen kil minerallerinin adsorpsiyon kapasitesinin işlenmemiş yüzeysel tortulardan $\mathrm{Cu}$ ve $\mathrm{Zn}$ için sırasıyla 1,6 ve 2,5 kat daha fazla olduğu tespit edilmiştir [5]. Tümsek vd. (2012), bentonit, sepiyolit ve zeolit kullanarak sulu çözeltiden nikel iyonlarının giderimi üzerine çalışmışlardır. Çözelti pH değeri ve sıcaklığının adsorpsiyon üzerindeki etkisi belirlenmiştir. Elde edilen sonuçlar Langmuir ve Freundlich izotermlerine göre değerlendirilmiştir. Doğal killerin adsorpsiyon yöntemi ile sulu çözeltilerden ağır metal giderimi üzerine ucuz ve bol bulunan bir alternatif adsorban olduğu görülmüştür [6]. Bir diğer çalışmada bakır ve çinkonun boksit ve montmorillonit tipi killer üzerinde adsorpsiyonunu incelemiștir. Yapılan çalışmada denge süresine 1 saat sonunda ulaşıldığı, bakır ve çinko adsorpsiyonunun adsorban dozu ve pH'ın artmasıyla yükseldiği bulunmuștur. Bakır ve çinko adsorpsiyonunun hem Freundlich hem de Langmuir izotermi ile iyi uyum sağladığı belirtilmiştir. Adsorpsiyon dengesine ulaşıldığı anda montmorillonit kilinin $\mathrm{Cu}^{+2}$ giderimi \%98, $\mathrm{Zn}^{+2}$ giderimi \%97; boksitin ise $\mathrm{Cu}^{+2}$ ve $\mathrm{Zn}^{+2}$ giderimi \%99 olarak bulmuştur [7]. Baştuğ (2008) ise yaptığ çalışmada, palmiye kökenli aktif karbon üzerinde bakırın adsorpsiyonunu incelemiş ve en uygun çalkalama süresini $40 \mathrm{dk}$ olarak belirlemiştir. $\mathrm{Pb}$ iyonları her iki adsorban üzerinde ilk 20 dakikada süratli adsorpsiyon eğilimi göstermişlerdir. $20 \mathrm{dk}$ sonunda $\mathrm{Pb}$ iyonları montmorillonit üzerinde en yüksek adsorpsiyon değerine ulaştığı için dönüm noktası olarak $20 \mathrm{dk}$ kabul edilmiştir. Ancak Pb iyonlarının tuğla kili üzerinde $40 \mathrm{dk}$ ya kadar adsorbe olmaya devam ettiği gözlemlenmiş olup, $40 \mathrm{dk}$ sonunda dönüm noktasına ulaştığı için $\mathrm{Pb}$ iyonlarının tuğla kili üzerinde adsorbe olması için gereken süre $40 \mathrm{dk}$ olarak kabul edilmiştir. Adsorpsiyon dengesine ulaşıldığı anda montmorillonit üzerinde $\mathrm{Pb}$ iyonları yaklaşık \%97,74, tuğla kili üzerinde ise yaklaşık $\% 98,65$ oranında adsorbe olmuştur [8]. Dönmez (2006), yaptığı çalışmada doğal kil minerallerinden olan fosfat kayası, klinoptilolit ve perlit ile atıksulardan $\mathrm{Pb}^{+2}$ iyonlarının $1 \mathrm{~g} / \mathrm{L}$ adsorban miktarlarında, $100 \mathrm{mg} / \mathrm{L}$ başlangıç $\mathrm{Pb}^{+2}$ çözeltisi konsantrasyonunda adsorsiyonunu incelemiş, en uygun çalkalama süresini her üç kil minerali için 15 $\mathrm{dk}$ belirlemiştir [9]. Yerlikaya (2008), yaptığı çalışmada bor endüstri atığı tarafından nikel (II) ve kursun (II) iyonlarının adsorpsiyonunu incelemiş, bu iki ağır metalin adsorban tarafından taşınmasını 90 $\mathrm{dk}$ içinde dengeye ulaştığını gözlemlemiştir [10]. Benzer alanda yine bor endüstri atı̆̆ kullanılarak bakırın adsorpsiyonu incelenmiş ve en uygun adsorban miktarı $2 \mathrm{~g} / \mathrm{L}$ olarak belirlenmiştir [11]. Doğal bentonit ile atıksudan $\mathrm{Pb}^{+2}$ iyonlarının adsorpsiyonunun incelendiği bir çalıșmada ise adsorpsiyonun $40 \mathrm{dk}$ da dengeye ulaştığı tespit edilmiştir [12]. Çevik vd. (2008), doğal bentonit minerallerinin nikel iyonlarını adsorplama kapasitesi üzerinde çalışmış, optimum bentonit miktarını 0,6 g/L olarak belirlemiştir [13]. Argun (2007) yaptığı çalışmada, $\mathrm{HCl}$ ile modifiye edilmiş çam kabuğu, çam kozalağı ve meşe talaşı üzerinde bakırın adsorpsiyonunu incelemiş, Fruendlich izotermine uyduğunu tespit etmiştir. $\mathrm{K}_{\mathrm{f}}$ değerlerini sırasıyla; $2,65,2,42$ ve 0,61 olarak bulmuştur [14]. Türkyılmaz (2011), yaptığı çalışmada kurşunun, mordenit kullanılarak sulu çözeltilerden adsorpsiyon prosesi ile gideriminin optimizasyonunu Langmuir, Freundlich, Redlich-Peterson ve Toth izotermlerini uygulayarak değerlendirmiş; kurşun adsorpsiyon verilerinin en iyi Freundlich izotermine uygunluk gösterdiği bulunmuştur [2].

Adsorpsiyon üzerinde $\mathrm{pH}$ etkisi de önemlidir. $\mathrm{Bu}$ konuda yapılan birçok çalışma bulunmaktadır. Çırakoğlu (2008), yaptığı çalışmada, valeks tanin reçinesi üzerinde çinkonun adsorpsiyonunu incelemiş ve en uygun $\mathrm{pH}$ değerini 4 olarak belirlemiştir. $\mathrm{Pb}$ adsorpsiyon çalışmasında $\mathrm{pH}$ etkisi tam olarak gözlemlenememiştir. Montmorillonit ve tuğla kili üzerinde yapılan $\mathrm{Ni}$ adsorpsiyon çalışmasında ise en uygun pH değeri her iki adsorban için 9 olarak kabul edilmiştir. Bunun nedeni artan $\mathrm{pH}$ ile adsorban yüzeylerinin daha negatif yüklü hale gelmesi ve nikel ile adsorbanların daha kolay etkileşime girebilmesidir [15].

$\mathrm{Bu}$ çalışmada amaç; boksit, montmorillonit kili ve tuğla yapımında kullanılan islahiye kili ile bakır, çinko, kurşun ve nikelin adsorpsiyon ile giderim oranlarını belirlemek ve optimum adsorban miktarları ve temas sürelerini ortaya çlkarmaktır. Böylece bölgede bol bulunan, ucuz ve kolay elde edilebilir materyallerin sulardan ağır metal gideriminde kullanım imkânları araștırılacaktır.

\section{Materyal ve Metot}

\subsection{Numunelerin hazırlanması}

Boksit minerali, Seydişehir Alüminyum İşletmelerinden temin edilerek İTÜ maden fakültesi laboratuvarlarında kil boyutunda öğütülmüştür. Saf 
su ile yıkanarak etüvde $105{ }^{\circ} C^{\prime}$ de kurutulmuş ve tekrar ufalanarak kil boyutunda elenmiștir. Yapısında \%32,4 böhmit, \%26 kaolinit, \%24,1 kalsit ve \%21,1 hematit bulunduğu belirlenmiștir. Montmorillonit kili, Kanada Saskachewan Üniversitesi'nde safsızlıklarından arındırılmış ve Çevre Mühendisliği laboratuvarlarına getirilmiştir. Montmorillonit 2:1 tipi kil sınıfına dahildir. Yapısal olarak, oktahedral bir tabaka ile birlikte bulunan alüminyum tabakayı çevreleyen iki tetrahedral yapılı silika levhalarından oluşmaktadır. Net yüzey yükü izomorfik yer değiştirme nedeniyle negatiftir. Mineral içeriği \%28,6 kalsiyen montmorillonit, \%15,1 albit, \%13 kuvars ve \%8,1 trioktahedral illit yüzdelerinden oluşmaktadır. Tuğla kili ise Gaziantep ili İslâhiye ilçesi Türkbahçe Köyü'nde faaliyet gösteren İstuk Tuğla Kiremit San. ve Tic. A.Ş. tarafından tuğla imalatı sırasında hammadde olarak kullanılmak üzere aynı adreste bulunan kil ocağından temin edilmiştir. \%15,2 düşük kuvars, \%34,2 muskovit, \%25,6 dolomit ve \%21,5 kaolinit içeriğinden oluşmaktadır. Tüm materyaller ögütülüp elendikten sonra 0.02 mm'den küçük boyutlarda hazırlanmış ve adsorpsiyon denemelerinde kullanılmıştır.

\section{2. Çözeltilerin hazırlanması}

$\mathrm{Cu}$ ve $\mathrm{Zn}$ çözeltilerini hazırlamak için (100 mg/L), $\mathrm{CuSO}_{4} .5 \mathrm{H}_{2} \mathrm{O}$ bileşiğinden $392,8 \mathrm{mg} ; \mathrm{ZnSO}_{4} .7 \mathrm{H}_{2} \mathrm{O}$ bileşiğinden $439,74 \mathrm{mg}$ alınarak $1 \mathrm{~L}$ saf suda çözünmüş ve 1'er L'lik $\mathrm{Cu}$ ve $\mathrm{Zn}$ çözeltileri hazırlanmıştır. Daha sonra istenen konsantrasyonlarda seyreltilmiştir. $\mathrm{Pb}$ ve $\mathrm{Ni}$ çözeltilerini hazırlamak için de $(100 \mathrm{mg} / \mathrm{L}), \mathrm{Pb}\left(\mathrm{NO}_{3}\right)_{2}$ bileşiğinden $0,16 \mathrm{~g}$; $\mathrm{Ni}\left(\mathrm{NO}_{3}\right)_{2} \cdot 6 \mathrm{H}_{2} \mathrm{O}$ bileşiğinden $0,5 \mathrm{~g}$ alınarak $1 \mathrm{~L}$ saf suda çözünmüş ve 1 'er L'lik $\mathrm{Pb}$ ve $\mathrm{Ni}$ çözeltileri hazırlanmıştır. Daha sonra istenen konsantrasyonlarda seyreltilmiştir. Adsorpsiyon testleri Batch metoduna göre yürütülmüştür yani proses kesikli olarak işletilmiştir. Deneylerde 50 ml'lik polipropilen tüpler kullanılmıştır. Adsorpsiyon yüzdeleri aşağıdaki formülle hesaplanmıştır:

$$
\text { Adsorpsiyon oranı }(\%)=\left(C_{0}-C_{t}\right) \times 100 / C_{0}
$$

$\mathrm{C}_{\mathrm{o}}:(\mathrm{mg} / \mathrm{L})$ başlangıç metal konsantrasyonu, $\mathrm{C}_{\mathrm{t}}$ : (mg/L) ise çözeltideki metal konsantrasyonunu göstermektedir. Temas süresini belirlemek için adsorban dozu $10 \mathrm{~g} / \mathrm{L}$ olarak seçilmiştir. Boksit, montmorillonit ve tuğla kili ile yapılan çalışmalarda $25 \mathrm{ml}$ çözelti ile çalışılmıştır $(0,25 \mathrm{~g}$ adsorban/25 ml çözelti).

\subsection{Optimum temas süresi ve adsorban dozu}

Zaman çalışmasında $\mathrm{Cu}$ ve $\mathrm{Zn}$ başlangıç konsantrasyonu $20 \mathrm{mg} / \mathrm{L}, \mathrm{Pb}$ ve $\mathrm{Ni}$ başlangıç konsantrasyonu $100 \mathrm{mg} / \mathrm{L}$ olarak seçilmiştir. Çalkalama işlemleri $150 \mathrm{rpm}$ ayarlı çalkalayıcıda gerçekleştirilmiştir. Ortam sıcaklığında ve doğal $\mathrm{pH}$ değerlerinde çalışılmıştır (Cu+boksit için pH: 5,65,
Zn+boksit için pH: 5,6; $\mathrm{Cu}+$ montmorillonit için pH: 5,45, Zn+montmorillonit için pH: 6,30, $\mathrm{Ni}+$ montmorillonit için $\mathrm{pH}: 6,68, \mathrm{Ni}+$ islahiye tuğla kili için $\mathrm{pH}$ : 6,86; $\mathrm{Pb}+$ montmorillonit için $\mathrm{pH}$ : 6,51, $\mathrm{Pb}+$ islahiye tuğla kili için $\mathrm{pH}$ : 6,83). Çalkalama sonrasında çözelti şırınga filtrelerden geçirilmiş ve elde edilen sıvıda $\mathrm{Cu}$ ve $\mathrm{Zn}$ analizleri Harran Üniversitesi Merkez Laboratuvarındaki Perkin Elmer Optima 5300 DV Optik Emisyon marka ICP cihazında yapilmıştır.

Adsorban miktarlarının etkisini belirlemek için başlangıç metal konsantrasyonları 77,6 mg/L Cu, 70 $\mathrm{mg} / \mathrm{L} \mathrm{Zn,} 100 \mathrm{mg} / \mathrm{L} \mathrm{Pb}$ ve $100 \mathrm{mg} / \mathrm{L} \mathrm{Ni}$ alınarak optimum temas süresince çalkalama yapılmıştır. Tüm kil tipleri için 1 ila $30 \mathrm{~g} / \mathrm{L}$ aralığında farklı adsorban dozları denenmiştir.

\subsection{Veri analizi}

Adsorpsiyon verilerinin analizleri Langmuir ve Freundlich izotermlerine göre yapılmıştır:

$$
\begin{aligned}
& \left(C_{e} / C_{s}\right)=\left(1 / Q_{0} \times b\right)+\left(C_{e} / Q_{0}\right) \\
& \log C_{s}=\log K_{f}+\left(1 / n_{f}\right) x \log C_{e}
\end{aligned}
$$

$\mathrm{Bu}$ denklemlerde $\mathrm{b}$ değeri Langmuir sabiti, $\mathrm{Q}_{0}$ adsorbe edilebilecek olan maksimum $\mathrm{Cu}, \mathrm{Zn}, \mathrm{Pb}$ ve $\mathrm{Ni}$ miktarıdır. Denklem $\mathrm{C}_{\mathrm{e}} / \mathrm{C}_{\mathrm{s}}$ ve $\mathrm{C}_{\mathrm{e}}$ değerleri arasında bir doğru belirttiği için, doğrunun eğimi $1 / Q_{0}$ değerini, doğrunun y ekseninde kestiği nokta ise $1 / \mathrm{Q}_{0} * \mathrm{~b}$ değerini vermektedir. $K_{\mathrm{f}}$ ve $1 / \mathrm{n}_{\mathrm{f}}$ deneysel Freundlich sabitleri, $\mathrm{C}_{s}(\mathrm{mg} / \mathrm{g})$ kile adsorbe olan miktar, $\mathrm{C}_{\mathrm{e}}$ $(\mathrm{mg} / \mathrm{ml})$ ise çözeltideki $\mathrm{Cu}, \mathrm{Zn}, \mathrm{Pb}$ ve $\mathrm{Ni}$ miktarı olarak verilmiştir. Denklem $\log \mathrm{C}_{\mathrm{e}}$ ve $\log \mathrm{C}_{\mathrm{s}}$ arasındaki bir doğruyu belirttiği için doğrunun eğimi $1 / n_{f}$ değerini, doğrunun y ekseninde kestiği nokta, log $\mathrm{K}_{\mathrm{f}}$ değerini verecektir.

\section{Bulgular}

\subsection{Adsorpsiyonda çalkalama süresinin etkisi}

$\mathrm{Cu}$ ve $\mathrm{Zn}$ iyonları boksit ve montmorillonit üzerinde ilk 15 dakikada süratli adsorpsiyon eğilimi göstermişlerdir. 1 saat sonra en yüksek adsorpsiyon değerlerine ulaşıldığı için dönüm noktası olarak 1 saat kabul edilmiştir. Adsorpsiyon dengesine ulaşıldığı anda montmorillonit ve boksit üzerinde başlangıç $\mathrm{Cu}$ konsantrasyonunun sırasıyla yaklaşık $\% 98$ ve \%99'u adsorbe olmuştur. Zn konsantrasyonunun ise yine sirasıyla montmorillonit ve boksit üzerinde \%97 ve \%99'u adsorbe olmuștur. 1 saatten sonra adsorpsiyon değerlerinde değişme olmamıştır (Şekil 1).

$\mathrm{Pb}$ iyonları montmorillonit üzerinde ilk 20 dakikada süratli adsorpsiyon eğilimi göstermiş olup tuğla kili üzerinde 40 dk'ya kadar adsorbe olmaya devam ettiği gözlemlenmiştir. $20 \mathrm{dk}$. sonunda $\mathrm{Pb}$ iyonları montmorillonit üzerinde en yüksek adsorpsiyon değerine ulaştığı için dönüm noktası olarak $20 \mathrm{dk}$., 
tuğla kili için dönüm noktası $40 \mathrm{dk}$. olarak kabul edilmiştir. Adsorpsiyon dengesine ulaşıldığı anda montmorillonit üzerinde $\mathrm{Pb}$ iyonları yaklaşık \%97,74, tuğla kili üzerinde ise yaklaşık \%98,65 oranında adsorbe olmuştur. $\mathrm{Ni}$ iyonlarının montmorillonit üzerinde çalkalama süresi $20 \mathrm{dk}$. olarak kabul edilmiştir. Ni iyonlarının tuğla kili üzerinde adsorbe olması için geçen süre de 4 saat olarak kabul edilmiştir. Adsorpsiyon dengesine ulaşıldığı anda montmorillonit üzerinde $\mathrm{Ni}$ iyonlarının yaklaşık \%75,30'unun, tuğla kili üzerinde ise yaklaşık \%45,89'unun adsorbe olduğu görülmüştür (Şekil 1).
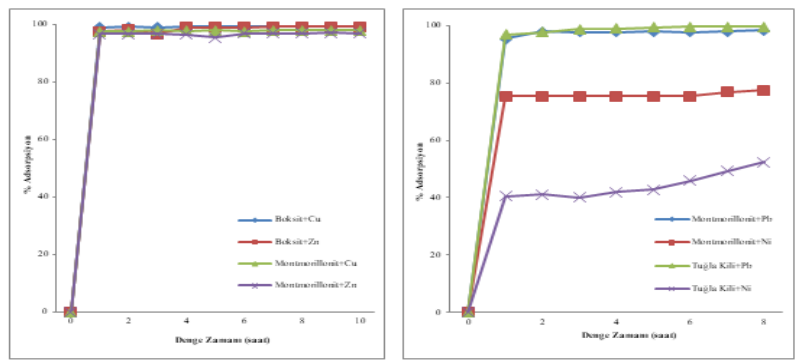

Şekil 1. Boksit, montmorillonit ve tuğla kili üzerinde zamana bağlı $\mathrm{Cu}, \mathrm{Zn}, \mathrm{Pb}$ ve $\mathrm{Ni}$ adsorpsiyon değerleri

\subsection{Adsorpsiyonda adsorban miktarının etkisi}

Başlangıç $\mathrm{Cu}, \mathrm{Zn}, \mathrm{Pb}$ ve Ni konsantrasyonları sırasıyla 77,55, 69,90, 103,2 mg/L ve 92,29 mg/L olarak çalışılmıştır. Adsorpsiyon değerleri tüm killer için artan kil dozu ile belirli oranlarda artmıştır. Bu durum, artan adsorban konsantrasyonu ile birlikte adsorpsiyon için gereken spesifik yüzey alanın da artması ile açıklanabilir. Ancak, belirli bir değerden sonra bir dönüm noktasına ulaşılmıştır (Şekil 2). Montmorillonit üzerinde $\mathrm{Cu}$ ve $\mathrm{Zn}$ adorpsiyonu ve boksit üzerinde $\mathrm{Cu}$ adsorpsiyonu $10 \mathrm{~g} / \mathrm{L}$ dozu için \%70'in üzerinde iken, boksit üzerinde $\mathrm{Zn}$ adsorpsiyonu \%45 düzeyinde kalmıştır. Her iki kil için $30 \mathrm{~g} / \mathrm{L}$ adsorban miktarlarında maksimum adsorpsiyona ulaşılmıştır, ancak bu değerin ekonomik olmayacağı düşünülmüştür.
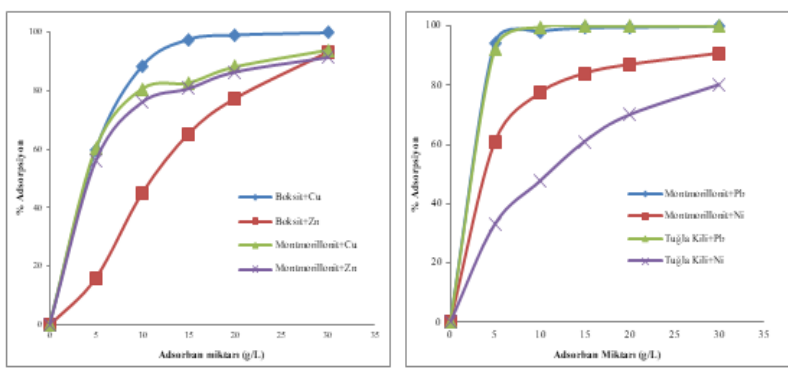

Şekil 2. Adsorban miktarlarına bağlı olarak $\mathrm{Cu}, \mathrm{Zn}, \mathrm{Pb}$ ve $\mathrm{Ni}$ adsorpsiyon değerleri

Montmorillonit üzerinde $\mathrm{Pb}$ adsorpsiyonu adsorban miktarı arttıkça yükselmiş ancak $10 \mathrm{~g} / \mathrm{L}$ adsorban miktarında \%98,12 adsorpsiyon düzeyinde iken daha sonra pek fazla değişim olmamıştır. Montmorillonit üzerinde $\mathrm{Ni}$ adsorpsiyonu için en uygun adsorban miktarı \%84,03 adsorpsiyon verimini veren $15 \mathrm{~g} / \mathrm{L}$ değeri kabul edilmiştir. Tuğla kili üzerinde $\mathrm{Pb}$ adsorpsiyonu için adsorban miktarı montmorillonit kili gibi $10 \mathrm{~g} / \mathrm{L}, \mathrm{Ni}$ adsorpsiyonu için \%61,04 adsorpsiyon verimini veren $30 \mathrm{~g} / \mathrm{L}$ adsorban miktarı kabul edilmiştir. Farklı kil ve metaller ile yapılan çalışma sonuçlarına göre belirlenen ve en yüksek adsorpsiyonun sağlandığı "optimum adsorban miktarları" Tablo 1'de sunulmuştur. Bundan sonra yapılan çalışmalarda bu optimum dozlar kullanılmıştır.

Tablo 1. Farklı killer için belirlenen optimum adsorban miktarları

\begin{tabular}{cc}
\hline $\begin{array}{c}\text { Çalışmanın yapıldı̆̆ı kil } \\
\text { ve metal ikilisi }\end{array}$ & $\begin{array}{c}\text { Optimum adsorban } \\
\text { miktarı (g/L) }\end{array}$ \\
\hline Montmorillonit+ $\mathrm{Pb}$ & 10 \\
Montmorillonit+Ni & 15 \\
Montmorillonit+Cu & 10 \\
Montmorillonit+Zn & 10 \\
Boksit+Cu & 10 \\
Boksit+ $\mathrm{Zn}$ & 30 \\
Tuğla kili+ $\mathrm{Pb}$ & 10 \\
Tuğla kili+Ni & 30 \\
\hline
\end{tabular}

\subsection{Adsorpsiyonda pH etkisi}

Üç kil tipi üzerinde ağır metal adsorpsiyonunda $\mathrm{pH}$ etkisi Şekil 3'te görülmektedir. pH 2 iken boksit ve montmorillonit üzerinde $\mathrm{Cu}$ adsorpsiyonu sırasıyla, $\% 23$ ve $\% 40, \mathrm{Zn}$ adsorpsiyonu ise $\% 6$ ve $\% 21$ bulunmuştur. $\mathrm{Cu}$ ve $\mathrm{Zn}$ adsorpsiyonu, boksit ve montmorillonit üzerinde $\mathrm{pH}$ değeri yaklaşık olarak 11 seviyelerinde maksimum düzeye ulaşmıştır. $\mathrm{Cu}$ ve Zn'nin özellikle boksit üzerindeki adsorpsiyon kapasiteleri $\mathrm{pH}$ artışından büyük oranda etkilenmişlerdir. pH değeri 2'den 11'e yükselirken $\mathrm{Cu}$ $\% 41$ 'den \%98'e, Zn adsorpsiyonu ise \%6'dan \%100'e yükselmiştir. $\mathrm{Bu}$ durum iyon yüklerinin, adsorban yüzeyindeki elektriksel çekim kuvvetini büyük oranda etkilediğini ve değiștirdiğini ortaya koymaktadır (Şekil 3).

Hem montmorillonit hem de tuğla kili için $\mathrm{Ni}$ ve $\mathrm{Pb}$ adsorpsiyonunda $\mathrm{pH}$ etkisi beklenildiği gibi gerçekleşmiş olup, pH değeri 3'ten 11'e yükselirken, $\mathrm{Ni}$ iyonlarının adsorpsiyonunun montmorillonit için adsorpsiyon yüzdesi \%70,24'ten \%99,59'a, tuğla kili üzerinde ise \%28,37'dan \%99,59'a yükseldiği görülmektedir. $\mathrm{Pb}$ iyonlarının adsorpsiyonunun montmorillonit için adsorpsiyon yüzdesi \%95,08'den \%99,53'e, tuğla kili için ise \%96,09'dan \%96,47'ye yükseldiği görülmüştür (Şekil 3).
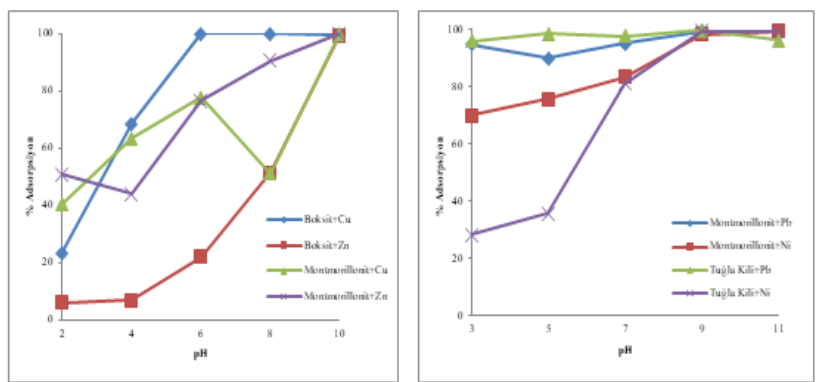

Şekil 3. Boksit, montmorillonit ve tuğla kili üzerinde $\mathrm{Cu}, \mathrm{Zn}$, $\mathrm{Pb}$ ve $\mathrm{Ni}$ adsorpsiyonunun $\mathrm{pH}$ ile değișimi 
Tablo 2. Bakır, Çinko, Kurșun ve Nikel adsorpsiyonuna ait Freundlich katsayıları ve adsorpsiyon dağılım sabitleri

\begin{tabular}{|c|c|c|c|c|c|}
\hline Adsorban & $K_{f}(\mathrm{~mL} / \mathrm{g})$ & $\log K_{f}(m L / g)$ & $\mathbf{n}_{\mathbf{f}}$ & $1 / n_{f}$ & $\mathbf{R}^{2}$ \\
\hline Boksit (Cu) & 4,179 & 0,6211 & 4,098 & 0,244 & $>0,97$ \\
\hline Montmorillonit $(\mathrm{Cu})$ & 1,978 & 0,2964 & 2,088 & 0,4788 & $>0,96$ \\
\hline Boksit (Zn) & 2,882 & 0,4597 & 6,230 & 0,1605 & $>0,95$ \\
\hline Montmorillonit (Zn) & 1,868 & 0,2715 & 2,037 & 0,4907 & $>0,98$ \\
\hline Montmorillonit (Pb) & 7,967 & 0,9013 & 2,911 & 0,3435 & $>0,86$ \\
\hline Tuğla Kili (Pb) & 9,729 & 0,9881 & 5,637 & 0,1774 & $>0,90$ \\
\hline Montmorillonit (Ni) & 1,548 & 0,1898 & 2,045 & 0,4891 & $>0,97$ \\
\hline Tuğla Kili (Ni) & 1,029 & 0,0126 & 3,341 & 0,2993 & $>0,98$ \\
\hline
\end{tabular}

Tablo 3. Bakır, Çinko, Kurșun ve Nikel adsorpsiyonuna ait Langmuir katsayıları ve adsorpsiyon dağılım sabitleri

\begin{tabular}{cccccc}
\hline Adsorban & Qo (mg/g) & $\mathbf{1 / Q o}(\mathbf{g} / \mathbf{m g})$ & $\mathbf{b ~ ( L / m g )}$ & $\mathbf{1 / Q o}$ *b (g/L) & $\mathbf{R}^{\mathbf{2}}$ \\
\hline Boksit (Cu) & 9,115 & 0,1097 & 0,757 & 0,1448 & 0,98 \\
Montmorillonit (Cu) & 8,136 & 0,1229 & 0,402 & 0,3052 & 0,96 \\
Boksit (Zn) & 5,197 & 0,1924 & 1,095 & 0,1756 & 0,99 \\
Montmorillonit (Zn) & 4.290 & 0,1298 & 0,386 & 0,3356 & 0,95 \\
Montmorillonit (Pb) & 37,313 & 0,0268 & 0,252 & 0,1064 & 0,98 \\
Tuğla Kili (Pb) & 25,062 & 0,0399 & 7,634 & 0,0983 & 0,98 \\
Montmorillonit (Ni) & 24,938 & 0,0401 & 0,028 & 1,4469 & 0,97 \\
Tuğla Kili (Ni) & 3,398 & 0,2943 & 0,169 & 1,734 & 0,97 \\
\hline
\end{tabular}

\subsection{Freundlich izotermine göre değerlendirilmesi}

Bakır ve çinko adsorpsiyonu tüm adsorbanlar için Freundlich adsorpsiyon eşitliğine uymaktadır $\left(\mathrm{R}^{2}>0,95\right)$. Boksit üzerinde, bakır ve çinkonun adsorpsiyonu $\mathrm{K}_{\mathrm{f}}$ değeri 4,179 ve 2,882 ile montmorillonit kilinden daha yüksek bulunmuştur (Tablo 1). Montmorillonit ve tuğla kili üzerinde nikel adsorpsiyonunun Freundlich izoterm modeline uyduğu ve montmorillonit üzerinde nikel adsorpsiyonunun $\mathrm{K}_{\mathrm{f}}$ değerinin 1,548, tuğla kili üzerinde nikel adsorpsiyonunun $\mathrm{K}_{\mathrm{f}}$ değerinden 1,029 yüksek bulunmasiyla $\mathrm{Ni}$ adsorspiyonunda montmorillonitin tuğla kiline göre adsorplama kapasitesi daha yüksek olduğu görülmüștür. Kurșununun $(\mathrm{Pb})$ tuğla kili ve montmorillonit üzerindeki Freundlich adsorpsiyon katsayıları sırasıyla 9,729 ve 7,967 olarak bulunmuștur. Kurşun adsorpsiyonunun Langmuir izotermine uyumu $\mathrm{R}^{2}=0,98$ ile daha yüksek olmuştur (Tablo 2 ).

\subsection{Langmuir izotermine göre değerlendirilmesi}

Bakır ve çinko adsorpsiyonu tüm adsorbanlar için Langmuir adsorpsiyon eşitliğine uymaktadır $\left(\mathrm{R}^{2}>0,95\right)$. Boksit üzerinde, bakır ve çinkonun adsorpsiyonu $Q_{0}$ değeri 9,115 ve 5,97 ile montmorillonit kilinden daha yüksek bulunmuştur (Tablo 3). Kurşun ve nikel adsorpsiyonunun her iki adsorban üzerinde Langmuir izotermine uygunluk sağladığı; montmorillonit üzerinde, kurşun ve nikel adsorpsiyonu sırasıyla $Q_{0}$ değeri 37,313 ve 24,938 ile tuğla kilinden daha yüksek bulunarak montmorillonitin kurşun ve nikeli adsorplamada tuğla kilinden daha yüksek kapasitede olduğu anlaşılmaktadır.

\section{Tartışma ve Sonuç}

$\mathrm{Bu}$ çalışmada, bakır çinko, kurşun ve nikelin adsorpsiyonu araştırılmıştır. $\mathrm{Bu}$ amaçla, düşük maliyetli birer malzeme olan montmorillonit, tuğla kili ve boksit kullanılarak en yüksek adsorpsiyon verimi elde edilmeye çalıșılmıștır. $\mathrm{Cu}$ ve $\mathrm{Zn}$ için kinetik testlerin sonucunda elde edilen çalkalama süreleri 1 saat olarak esas alınmıștır. $\mathrm{Pb}^{+2}$ iyonları montmorillonit üzerinde en yüksek adsorpsiyon değerine ulaştığı için dönüm noktası $20 \mathrm{dk}$, tuğla kili üzerinde adsorbe olması için gereken süre ise $40 \mathrm{dk}$ olarak kabul edilmiştir. $\mathrm{Ni}^{+2}$ iyonlarının montmorillonit üzerinde çalkalama süresi $20 \mathrm{dk}$, tuğla kili üzerinde adsorbe olması için gereken süre ise geçen süre 4 saat olarak belirlenmiștir. Adsorban miktarını belirlemek için yapılan deneylerde ise, 10 g/L'lik adsorban dozunda $\mathrm{Cu}, \mathrm{Zn}$ ve $\mathrm{Pb}$ konsantrasyonlarının yaklaşık büyük bir kısmı adsorbe olduğundan, sonraki çalışmalar da adsorban miktarları $10 \mathrm{~g} / \mathrm{L}$ olarak seçilmiştir. Montmorillonit üzerinde nikel adsorpsiyonu için dönüm noktası pek belirgin olmadığı için en uygun adsorban miktarı $\% 84,03$ adsorpsiyon verimini veren $15 \mathrm{~g} / \mathrm{L}$, tuğla kili üzerinde nikel adsorpsiyonunda $30 \mathrm{~g} / \mathrm{L}$ adsorban miktarı kabul edilmiştir. Optimum adsorban dozları belirlendikten sonra bu miktarların üzerinde malzeme kullanımı önerilmemektedir. Giderim maliyetlerini arttıracağı ve kirlenmiş adsorban malzemenin son bertarafında yaşanacak sıkıntılar da göz önünde bulundurularak optimum dozların uygulanması önem arz etmektedir. Adsorpsiyonda pH'nın etkisini ve en uygun değeri belirlemek için yapılan deneylerde, $\mathrm{pH}$ değeri boksit üzerinde $\mathrm{Cu}$ ve Zn için sırasıyla 7,5 ve 10,9 , montmorillonit kili üzerinde ise 10,9 ve 10,6 olarak tespit edilmiștir. Montmorillonit ve tuğla kili üzerinde yapılan nikel adsorpsiyon çalışmasında en uygun $\mathrm{pH}$ değeri her iki adsorban için 9 olarak kabul edilmiştir. Adsorpsiyon dengesine ulaşıldı $\breve{g}$ anda montmorillonit ve boksit üzerinde bașlangıç $\mathrm{Cu}$ konsantrasyonunun sırasıyla yaklaşık \%98 ve \%99'u adsorbe olmuştur. Zn konsantrasyonunun ise yine sirasiyla montmorillonit ve boksit üzerinde \%97 ve \%99'u adsorbe olmuştur. 
Adsorpsiyon dengesine ulaşıldığı anda montmorillonit kilinin $\mathrm{Pb}^{+2}$ giderimi $\% 97,74, \mathrm{Ni}^{+2}$ giderimi \%75,30; tuğla kilinin $\mathrm{Pb}^{+2}$ giderimi \%98,65, $\mathrm{Ni}^{+2}$ giderimi ise \%45,89 olarak bulunmuştur. Boksit ve montmorillonit kili üzerinde $\mathrm{Cu}$ ve $\mathrm{Zn}$ adsorpsiyonunun Langmuir ve Freundlich izotermlerine göre değerlendirilmesi yapılmış ve çlkan değerler $\left(\mathrm{R}^{2}>0,95\right)$ adsorpsiyonun her iki izoterme de uyduğunu göstermiştir. Boksit üzerinde, bakır ve çinkonun adsorpsiyonu montmorillonit kilinden daha yüksek bulunmuştur. Montmorillonit üzerinde, kurşun ve nikel adsorpsiyonu tuğla kilinden daha yüksek çıkmıştır.

\section{Kaynakça}

[1] Fırat, B., 2007. Atık sulardan kurşun (II) ve bakır (II) iyonlarının yumurta kabuğu ile uzaklaştırılması ve optimum koşulların belirlenmesi. Gazi Üniversitesi, Fen Bilimleri Enstitüsü, Yüksek Lisans Tezi, 154s, Ankara.

[2] Türkyılmaz, H., 2011. Kurşun iyonlarının kesikli adsorpsiyon prosesi ile gideriminin cevap yüzey yöntemiyle optimizasyonu. Süleyman Demirel Üniversitesi, Fen Bilimleri Enstitüsü, Yüksek Lisans Tezi, 85s, Isparta.

[3] Bamgbose, J. T., Adewuyi, S., Bamgbose, O., Adetoye, A. A., 2010. Adsorption kinetics of cadmium and lead by chitosan. African Journal of Biotechnology, 9(17): 2560-2565.

[4] Bamidele, I., Unuabonah, I. E., Olu-Owolabi, B. I., 2010. Adsorption of $\mathrm{Zn}^{+2}$ and $\mathrm{Cu}^{+2}$ onto sulphate and phosphate-modified bentonite. Applied Clay Science, 51: 170-173.

[5] Wang, X., Li, Y., 2011. Measurement of $\mathrm{Cu}$ and $\mathrm{Zn}$ adsorption onto surficial sediment components: New evidence for less importance of clay minerals. Journal of Hazardous Materials, 189(2011): 719-723.

[6] Tümsek, F., Karabacakoğlu, B., 2012. Nikel (II) iyonunun sulu ortamdan Granül Aktif Karbon (GAK) ile giderilmesi. Eskişehir Osmangazi Üniversitesi, BAÜ Fen Bilimleri Enstitüsü Dergisi, 14(2):1-6.
[7] Bilgiç, B., 2013. Bakır ve çinkonun boksit ve montmorillonit tipi killer üzerinde adsorpsiyonu. Harran Üniversitesi, Fen Bilimleri Enstitüsü, 78s, Şanlıurfa.

[8] Baştuğ, F., 2008. Palmiye kabuğu kökenli aktif karbon adsorpsiyonu ile ağır metal giderimi. Süleyman Demirel Üniversitesi, Fen Bilimleri Enstitüsü, Yüksek Lisans Tezi, 92s, Isparta.

[9] Dönmez, R., 2006. Doğal kil mineralleri kullanarak atık sulardan kurşun (II) iyonunun adsorpsiyonu. Celal Bayar Üniversitesi, Fen Bilimleri Enstitüsü, Yüksek Lisans Tezi, 117s, Manisa.

[10] Yerlikaya, E., 2008. Atık sulardan nikel (II) ve kurşun (II) iyonlarının adsorpsiyon metoduyla uzaklaştırılması. Dumlupınar Üniversitesi, Fen Bilimleri Enstitüsü, Kimya Anabilim Dalı, Yüksek Lisans Tezi, 69s, Kütahya.

[11] Karakaya, G., 2008. Atık sulardan bakır (II) ve kobalt (III) iyonlarının adsorpsiyon metoduyla uzaklaştırılması. Dumlupınar Üniversitesi, Fen Bilimleri Enstitüsü, Yüksek Lisans Tezi, 55s, Kütahya.

[12] Özcan, A. S., 2010. Doğal bentonitin karakterizasyonu ve kurşun (II) iyonlarını adsorpsiyon yeteneği. BAÜ Fen Bilimleri Enstitüsü Dergisi, 12(2): 85-97.

[13] Çevik, T., Top, S., Sekman, E., Yazıcı, R., BİLGİLİ, S., 2008. Nikelin bentonitle adsorpsiyonunun izoterm, kinetik ve termodinamik analizi, Üniversite Öğrencileri III. Çevre Sorunları Kongresi, İstanbul.

[14] Argun, M. E., 2007. Kimyasal olarak modifiye edilmiş adsorbanlar kullanarak ağır metal iyonlarının adsorpsiyonu. Selçuk Üniversitesi, Fen Bilimleri Enstitüsü, Doktora Tezi, 170s, Konya.

[15] Çırakoğlu, S., 2008. Zn+2'nin valeks tanin reçinesiyle adsorpsiyonu ve geri kazanılması. Sakarya Üniversitesi, Fen Bilimleri Enstitüsü, Yüksek Lisans Tezi, 106s, Sakarya. 